\title{
Addendum
}

\section{PROSODIC PATTERNS IN SYLHETI-ENGLISH BILINGUALS - ADDENDUM}

\section{Kathleen M. McCarthy}

\section{Esther de Leeuw}

DOI: https://doi.org/10.1017/S027226312100036X, published online by Cambridge University Press, 2 August 2021.

The authors of this article (McCarthy \& de Leeuw, 2021) would like to supply the following author contribution statement:

Both authors contributed equally to the conceptualization and design of the project, with KMM leading the Sylheti language and community aspects and EdeL leading the prosodic aspects of the study. KMM collected the data. Both KMM and EdeL conducted the acoustic analysis. KMM conducted the statistical analysis with input from EdeL. Both authors wrote the manuscript.

\section{REFERENCE}

McCarthy, K. M., \& de Leeuw, E. (2021) Prosodic patterns in Sylheti-English bilinguals. Studies in Second Language Acquisition. Advance online publication. https://doi.org/10.1017/S027226312100036X 